\title{
Reimplante intencional como última opción de tratamiento frente al fracaso endodóntico. Revisión narrativa.
}

\author{
Intentional replantation as the last treatment option for endodontic \\ failure. A narrative review \\ Nicolás Dufey Portilla ${ }^{1 \mathrm{a}}$ (D), Fernando Peña-Bengoa ${ }^{1 \mathrm{~b}}$ (D), Leonardo Lazo Drpic ${ }^{1 \mathrm{c}}$
}

\section{RESUMEN}

El fracaso endodóntico, caracterizado por la persistencia de una lesión inflamatoria peri-radicular en un diente previamente tratado, muestra una prevalencia del 16 a $65 \%$ de la población mundial. Ante esto, existen diversas opciones de tratamiento, incluyendo el retratamiento endodóntico no quirúrgico y la microcirugía apical. En algunas ocasiones estas opciones no son viables, surgiendo el reimplante intencional como alternativa a la extracción dentaria.

Objetivo: Analizar aspectos clínicos, secuencia de tratamiento, principios técnicos y biológicos y resultados clínicos del reimplante intencional.

Conclusión: En casos de enfermedad endodóntica posttratamiento, donde no sea posible el retratamiento convencional y las limitaciones anatómicas impidan realizar la microcirugía apical, el reimplante intencional puede ser considerado como alternativa viable de tratamiento.
1. Facultad de Odontología, Universidad Andres Bello, Viña del Mar, Chile.

a. Instructor, Departamento de Endodoncia, Facultad de Odontología, Universidad Andres Bello.

b. Profesor asistente, Departamento de Endodoncia, Facultad de Odontología, Universidad Andres Bello.

c. Alumno de Pregrado, Facultad de Odontología, Universidad Andres Bello

Correspondencia:

Nicolás Armando Dufey Portilla dufeyportilla@gmail.com

PALABRAS CLAVES:

Endodoncia; Reimplante Dental;

Tratamiento de Conductos Radiculares; Microcirugía endodóntica; Apicectomía.

\section{KEYWORDS:}

Endodontics; Tooth Replantation; Root Canal Therapy; Microsurgery;

Apicectomy. 


\begin{abstract}
Endodontic failure, characterized by the persistence of a peri-radicular inflammatory lesion in a previously treated tooth, shows a prevalence of 16 to $65 \%$ of the world population. There are different treatment options, including non-surgical endodontic retreatment and apical microsurgery. On some occasions, these options are not viable, and intentional replantation appears as an alternative to tooth extraction.
\end{abstract}

Objective: To analyze clinical aspects, treatment sequence, technical and biological principles, and clinical results of intentional replantation.

Conclusion: In cases of post-treatment endodontic disease, where conventional retreatment is not possible and anatomical limitations exclude the option of apical microsurgery, intentional replantation can be considered as a viable treatment alternative.

\section{INTRODUCCIÓN}

La enfermedad endodóntica post-tratamiento, definida como la persistencia o desarrollo de una lesión inflamatoria periapical o periradicular en un diente previamente tratado, es una situación relevante tanto para los pacientes como los tratantes, cuya prevalencia se encuentra entre un 16 a $65 \%$ de la población ${ }^{1}$. $\mathrm{Su}$ principal causa corresponde a la presencia de microorganismos en el sistema de conductos radiculares y/o tejidos periapicales ${ }^{2}$. Ante esto, diferentes opciones de tratamiento con variables resultados han sido sugeridas, incluyendo el retratamiento endodóntico no quirúrgico y la microcirugía apical. Debido a algunas limitaciones de esta última, como el acceso a ciertas zonas anatómicas, el reimplante intencional (RI) es propuesto como técnica clínica para resolver la enfermedad endodóntica post-tratamiento en casos específicos.
El RI es definido como la extracción programada de un diente, donde posterior a una evaluación de superficie radicular, eliminación de la causa del fracaso endodóntico y posterior reparación, se reposiciona en su alveolo original ${ }^{3}$, teniendo como objetivo principal resolver la enfermedad endodóntica en casos donde una microcirugía apical no es viable. En el siglo XI, el médico árabe Albucasis describió el primer caso de un reimplante, reposicionando y ferulizando dientes extraídos por factores periodontales, pero desde los siglos XVI a XVIII se comenzó a masificar, incluyendo técnicas que incorporaron la resección radicular y retro-obturación previo a la reimplantación ${ }^{3}$. Tal como en la microcirugía apical, las técnicas, materiales e instrumental utilizados han ido evolucionando a través de los años, pudiendo establecer en base a la evidencia científica, protocolos actuales con tasas de sobrevivencia que fluctúan en el rango del 88$95 \%{ }^{3,4}$. En base a la evidencia disponible, el objetivo del presente estudio es analizar los aspectos clínicos, secuencia de tratamiento, principios técnicos-biológicos y resultados clínicos actuales del procedimiento.

\section{INDICACIONES}

\section{CONTRAINDICACIONES}

Las indicaciones específicas de RI incluyen principalmente circunstancias en donde una microcirugía apical no es viable; en áreas anatómicas de limitado acceso y visibilidad, proximidad a estructuras nobles, condiciones donde el retratamiento no quirúrgico no ofrezca un buen pronóstico y por motivos económicos en que el paciente no pueda optar por la instalación de un implante $e^{4,5}$.

Las contraindicaciones reportadas incluyen todas aquellas en que el fracaso del tratamiento endodóntico puede ser resuelto mediante microcirugía apical. Desde un punto de vista anatómico se deben incluir en esta categoría raíces divergentes y/o muy curvas las cuales se podrían fracturar durante la extracción, fractura evidente de la pieza dentaria, dientes no rehabilitables, o presencia de corticales óseas reabsorbidas o ausentes ${ }^{6-9}$. Si existe un severo 
compromiso periodontal, al igual que en la microcirugía apical, la contraindicación es absoluta $^{3}$. El ligamento periodontal (LP) es esencial para el pronóstico, ya que, la sobrevivencia de sus células es un factor crítico para la regeneración y reintegración de los tejidos, y por ende para el éxito del reimplante intencional ${ }^{3}$. Es fundamental considerar dichas situaciones para la correcta elección de tratamiento, determinar un claro pronóstico pre y postoperatorio y prevenir posibles complicaciones durante el procedimiento.

El reimplante intencional, por lo tanto, ha sido avalado en la literatura para el tratamiento de fracturas radiculares verticales, perforaciones, reabsorciones radiculares externas, defectos periodontales debido a surcos radiculares, sinusitis maxilar de origen periapical y conductos tipo c-shaped en donde no hay solución vía ortógrada o mediante microcirugía apical ${ }^{10,11}$. En estas situaciones clínicas el reimplante podría ser considerado como modalidad de tratamiento frente a la extracción dentaria, permitiéndole al paciente conservar su diente.

\section{SELECCIÓN DE CASO Y PREOPERATORIO}

Al igual que en los procedimientos endodónticos quirúrgicos, se debe realizar una correcta anamnesis próxima y remota del paciente y diente involucrado, un examen clínico que incluya un adecuado diagnóstico general bucal (mucosa, dientes, lengua, estado gingival y periodontal), pruebas de sensibilidad, percusión, palpación y sondaje periodontal. Estos exámenes son esenciales para determinar si el paciente es apto para cirugía menor ambulatoria y predecir el pronóstico del procedimiento. Asimismo, debemos considerar:

- Exámenes imagenológicos: La radiografía retroalveolar y la tomografía computarizada de haz cónico son fundamentales. Esta última proporciona valiosa información respecto a la anatomía radicular externa y del sistema de conductos, la ubicación de posibles defectos del tratamiento endodóntico y la relación de los ápices con estructuras anatómicas adyacentes ${ }^{12}$. Estos complementos sumados a una correcta anamnesis y examen clínico son primordiales para la selección y planificación del caso.

- Consentimiento informado: El paciente debe estar en conocimiento de las distintas opciones de tratamiento, procurando hacer énfasis en los riesgos y beneficios, lo cual debe ser consignado en un documento de consentimiento. Los riesgos de este tipo de procedimiento y que el paciente debe considerar son: fractura dentaria (coronal y/o radicular) al momento de la extracción, daño a la restauración o rehabilitación coronaria presente, daño al diente adyacente, reabsorción radicular y/o anquilosis posterior al reimplante ${ }^{7}$. En este sentido, el paciente debe evaluar los pros y contras, sin embargo, cuando el tratamiento es viable es importante considerar que su elección se basa en ser la única opción frente a la extracción definitiva del diente involucrado.

- Premedicación antibiótica: La mayoría de los autores coinciden en no prescribir antibióticos preoperatorios en pacientes ASA I y II, guardando su prescripción solo para la prevención de endocarditis bacteriana subaguda (EBSA) y en pacientes portadores de prótesis articulares artificiales, comenzando la terapia el día previo o el mismo día del procedimiento ${ }^{7}$. Los antibióticos en estos casos pueden ser: penicilinas, ampicilinas, macrólidos, lincosamidas, y tetraciclinas ${ }^{3}$.

- Preparación del sitio quirúrgico: Se debe realizar el desbridamiento local de placa y cálculo dental, además de prescribir colutorios de clorhexidina en concentraciones de 0.12 a $2 \%$ comenzando el día previo al procedimiento con la finalidad de disminuir la carga microbiana oral $^{3,7}$. También se recomienda instalar separadores elásticos de ortodoncia en los contactos proximales del diente a tratar 3 a 4 días previo al procedimiento, logrando así una 
pequeña movilidad horizontal de 1 a $2 \mathrm{~mm}$ que facilitaría la extracción dentaria ${ }^{7}$.

- $\quad$ Número de operadores: La mayoría de los estudios han realizado el procedimiento mediante un solo operador, con resultados similares ${ }^{3}$. Sin embargo, diversos autores recomiendan 2 operadores al momento de la cirugía ${ }^{3}$, uno para realizar la extracción y otro para la manipulación quirúrgica-endodóntica. Esta opción se basa en el aumento de la eficiencia del tiempo operatorio, reduciendo el tiempo extraoral del diente, lo cual jugaría a favor del pronóstico postoperatorio al preservar mayor cantidad de células viables del ligamento periodontal responsables de la futura reintegración.

\section{PRINCIPIOS Y TÉCNICA}

Los principios técnicos y biológicos del RI son los mismos de la microcirugía apical moderna realizando la manipulación de los tejidos dentarios de manera extraoral;

\section{Exodoncia}

Esta crucial y sensible acción quirúrgica debe ser atraumática, minimizando el daño al ligamento periodontal. Se debe evitar el uso de elevadores, ya que, generan daño a la superficie radicular y cresta alveolar, limitándose al uso de luxadores y fórceps en la porción coronal del diente ${ }^{7}$. Para luxar el diente con mínimo trauma, una hoja de bisturí número $15 \mathrm{c}$ se debe introducir en dirección paralela al espacio del LP realizando la sindesmotomía, para luego realizar con fórceps un movimiento lento, controlado, prolongado y constante en dirección vestíbulolingual/palatino hasta conseguir desplazamiento dental vertical, momento donde se puede realizar un movimiento rotatorio para prevenir y mitigar el potencial daño a las células del ligamento periodontal ${ }^{3,7}$. La posible fractura de la corona o la raíz del diente durante la extracción es técnicodependiente, siendo descrita en el $5 \%$ de los $\operatorname{casos}^{13}$.

Una vez extraído, la manipulación del diente en todo momento debe ser mediante una gasa estéril humectada con suero fisiológico ${ }^{14}$ (figura 1), sujetando y rodeando la corona del diente, lo que asegura una hidratación continua para las células del LP cervicales y superficie radicular, además de suministrar los iones esenciales para las mismas ${ }^{3,7}$. Otro método de manipulación es mediante un fórceps sujetando solo la corona (figura 1), asegurando una presión constante en los mangos y procurando sumergir el diente en suero fisiológico de manera regular ${ }^{15}$. Por otro lado, el alveolo debe ser protegido de debris y saliva, cubriéndolo con una gasa estéril ${ }^{13}$.

Figura 1: Formas recomendadas para manipular el diente extraído

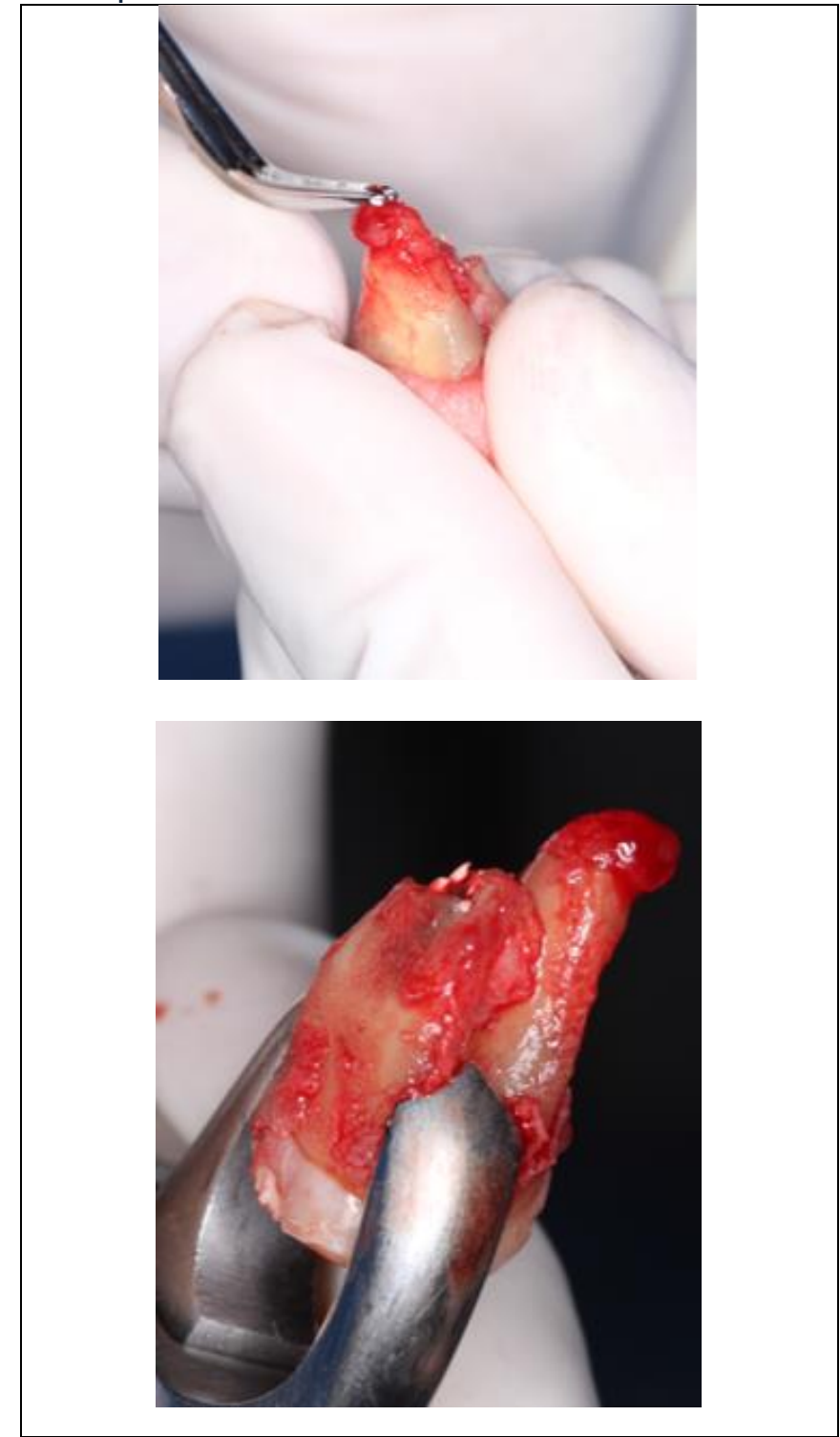

Imagen superior manipulación manual. Imagen inferior manipulación mediante fórceps.

*Imágenes de caso clínico de los autores del presente estudio. 
Las etapas posteriores a la extracción y previas a la reimplantación se deben realizar en un tiempo extraoral inferior a 15 minutos para asegurar la máxima vitalidad de las células del ligamento periodontal ${ }^{7}$. Este aspecto es crucial en el tratamiento y es el principal predictor de fracaso, con un riesgo de complicaciones (reabsorción externa y/o anquilosis) 1.7 veces más grande para los dientes reimplantados en un tiempo mayor, donde se ve comprometida la sobrevivencia de las células del LP expuestas al ambiente extraoral ${ }^{13,16}$.

Luego de la extracción y previo a la manipulación endodóntica-quirúrgica, se debe inspeccionar la porción radicular (figura 2), idealmente bajo magnificación y tinción con azul de metileno, en busca de fracturas, conductos accesorios, istmos, y cualquier factor anatómico adicional que requiera atención ${ }^{3,13}$.

Figura 2: Inspección del diente extraído.

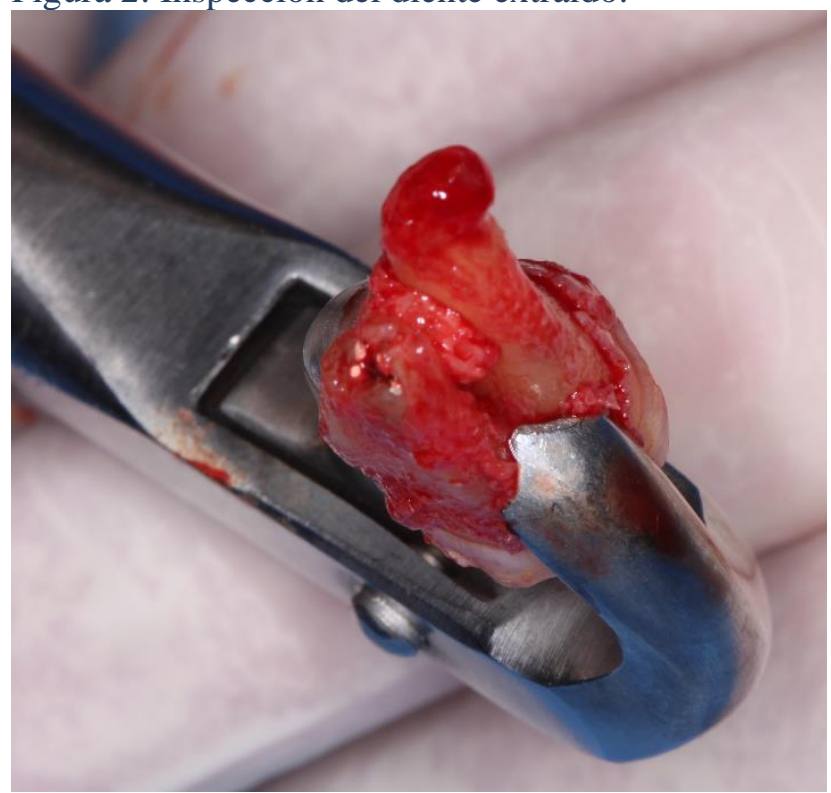

*Imágenes de caso clínico de los autores del presente estudio.

\section{Apicectomía}

Corresponde a la resección radicular apical del diente involucrado, utilizando instrumental rotatorio de alta velocidad, cortando mínimo $3 \mathrm{~mm}$ de longitud, lo que ha demostrado eliminar el $98 \%$ de las ramificaciones apicales y el $93 \%$ de los conductos laterales ${ }^{17}$ (figura 3 A y B). En esta modalidad de tratamiento, se prefiere el uso de fresas de carbide de alta velocidad por sobre el ultrasonido, debido a su mayor eficiencia de corte, reduciendo el tiempo clínico de esta etapa, en favor de un menor tiempo extraoral del diente ${ }^{18}$. De persistir tejido quístico y/o granulomatoso adherido a la superficie radicular, se debe eliminar cautelosamente con microcuretas y pinzas si permanece posterior a la resección ${ }^{3}$, sin dañar tejido sano.

\section{Preparación y obturación a retro}

Luego de la resección radicular, los conductos deben ser preparados para recibir el material de obturación, esto puede ser realizado mediante insertos ultrasónicos, siempre bajo abundante refrigeración. La profundidad de la preparación debe ser de al menos $3 \mathrm{~mm}$ y acorde a la anatomía original del sistema de conductos ${ }^{19}$ (figura $3 \mathrm{C}$ y D).

Luego se debe realizar la obturación a retro, posicionando y condensando un material idealmente de tipo biocerámico de primera o segunda generación (figura $3 \mathrm{E}$ ) de rápido fraguado, los cuales han demostrado buen sellado, gran biocompatibilidad y bioactividad con precipitación de cristales de apatita en las superficies dentinarias involucradas ${ }^{20,21}$, en favor de la reparación de los tejidos periradiculares.

Cabe destacar que los procedimientos descritos presentan algunas ventajas respecto a su realización en la microcirugía apical; las áreas radiculares pueden ser visualizadas de manera completa, sin dañar tejidos periodontales circundantes y sin la necesidad de osteotomía, en favor de un menor trauma postoperatorio, contribuyendo a la regeneración de los tejidos y requiriendo de un menor tiempo clínico.

\section{Reimplantación}

Previo a esta etapa, se debe realizar el curetaje del alveolo, limitado solo a la zona afectada por tejido granulomatoso $\mathrm{o}$ remanentes quísticos, generalmente restringidos a la 
Figura 3: Preparación y obturacion a retro.

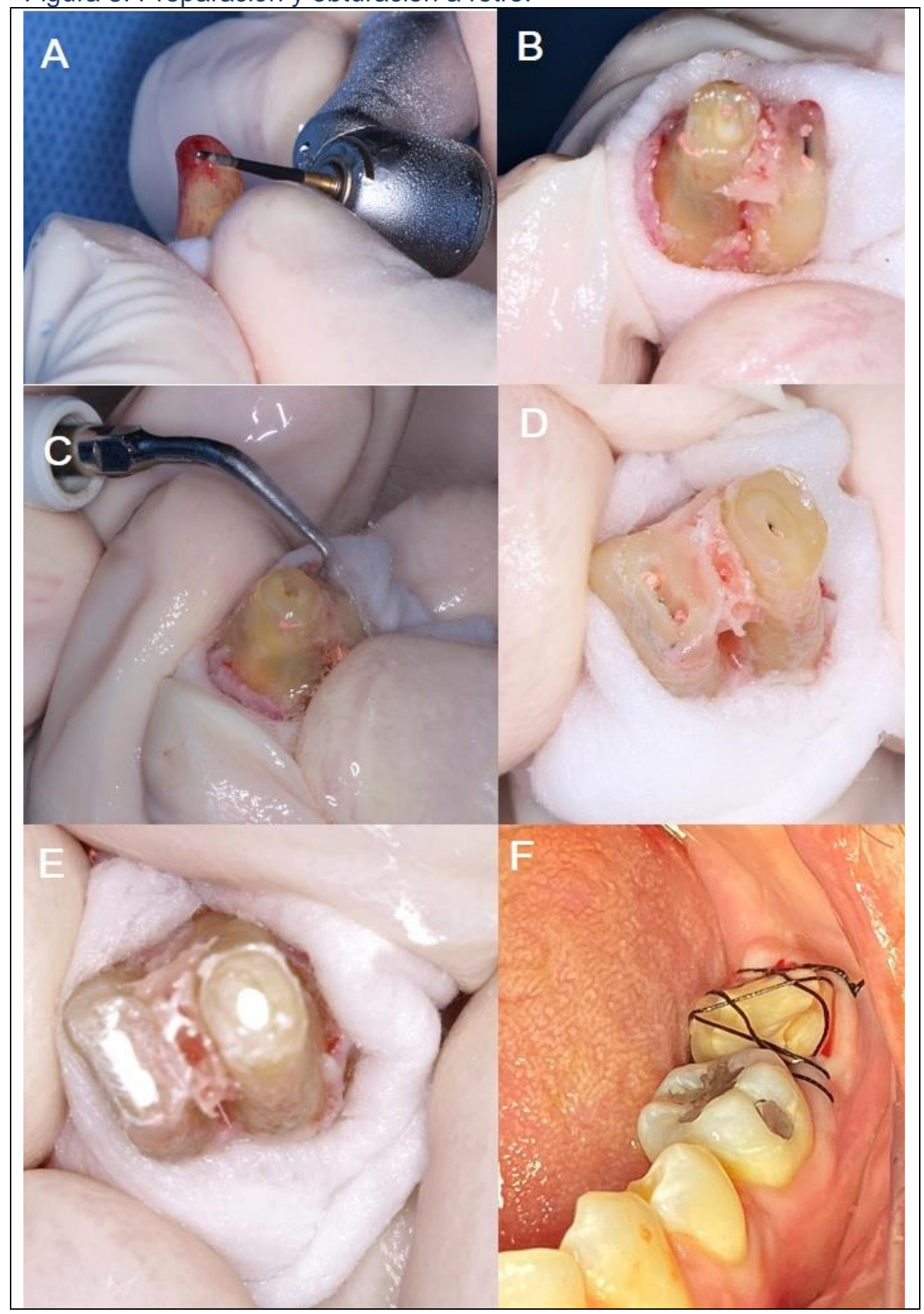

(A y B) Resección radicular. (C y D) Preparación a retro mediante ultrasonido y constante irrigación con suero fisiológico. (E) Obturación a retro mediante un material de tipo biocerámico. (F) Reimplante y sutura necesaria para conseguir la estabilización.

*Imágenes de caso clínico de los autores del presente estudio.

porción apical, evitando contactar y dañar las paredes alveolares indemnes, en donde se encuentran células del $\mathrm{LP}^{3}$. Así mismo, se debe irrigar el alveolo con suero fisiológico ${ }^{6}$. Una vez concluida esta etapa se realiza la reimplantación del diente en su alveolo original, introduciéndolo en dirección axial mediante presión digital, hasta lograr la posición original ${ }^{3}$. La evidencia sostiene que el uso de una férula flexible se debe realizar solamente si es necesario en casos de raíces 
cortas o falta de hueso interseptal ${ }^{22}$, y sujeta al grado de movilidad presentada posterior a la reimplantación ${ }^{7}$. De ser ferulizado, este debe permanecer por 2 semanas, ya que, la reinserción de los tejidos conectivos del ligamento periodontal de la superficie radicular y la pared del alveolo se produce en este periodo de tiempo ${ }^{8}$. Finalmente, se debe realizar una sutura suspensoria para asegurar la estabilización dentaria durante el proceso de reinserción de los tejidos ${ }^{8}$ (figura $3 \mathrm{~F})$.

Luego, el paciente debe mantener una presión constante sobre el diente reimplantado mordiendo una gasa estéril por un periodo de 10 minutos, y posteriormente el clínico deberá evaluar su estabilidad en el alveolo. Si aún presenta movilidad, esta presión se deberá mantener por 10 minutos más ${ }^{6}$. El ajuste oclusal es clave para evitar contactos prematuros que puedan desestabilizar el asentamiento del diente reimplantado $^{3}$, y en conjunto con la radiografía retroalveolar se debe evaluar la posición del diente en su alveolo posterior al procedimiento. Al comparar la imagen postoperatoria con la radiografía preoperatoria es esperable observar una zona radiolúcida apical correspondiente a la resección apical (figura 4).

Los cuidados postquirúrgicos a indicar incluyen gasa estéril compresiva por un periodo de dos horas inmediatamente finalizada la reimplantación, enjuague de clorhexidina al $0.12 \%$ por una semana comenzando el día siguiente al procedimiento, dieta blanda, evitar masticar en el sitio quirúrgico, analgésicos y antiinflamatorios no esteroidales, y frío local externo en intervalos de 15 minutos durante las primeras 24 horas.

\section{Seguimiento y control}

Los dientes reimplantados deben tener un riguroso control clínico-imagenológico periódico. Se considera un tratamiento exitoso cuando se observa ausencia o
Figura 4: Radiografías retroalveolares de diente 3.7

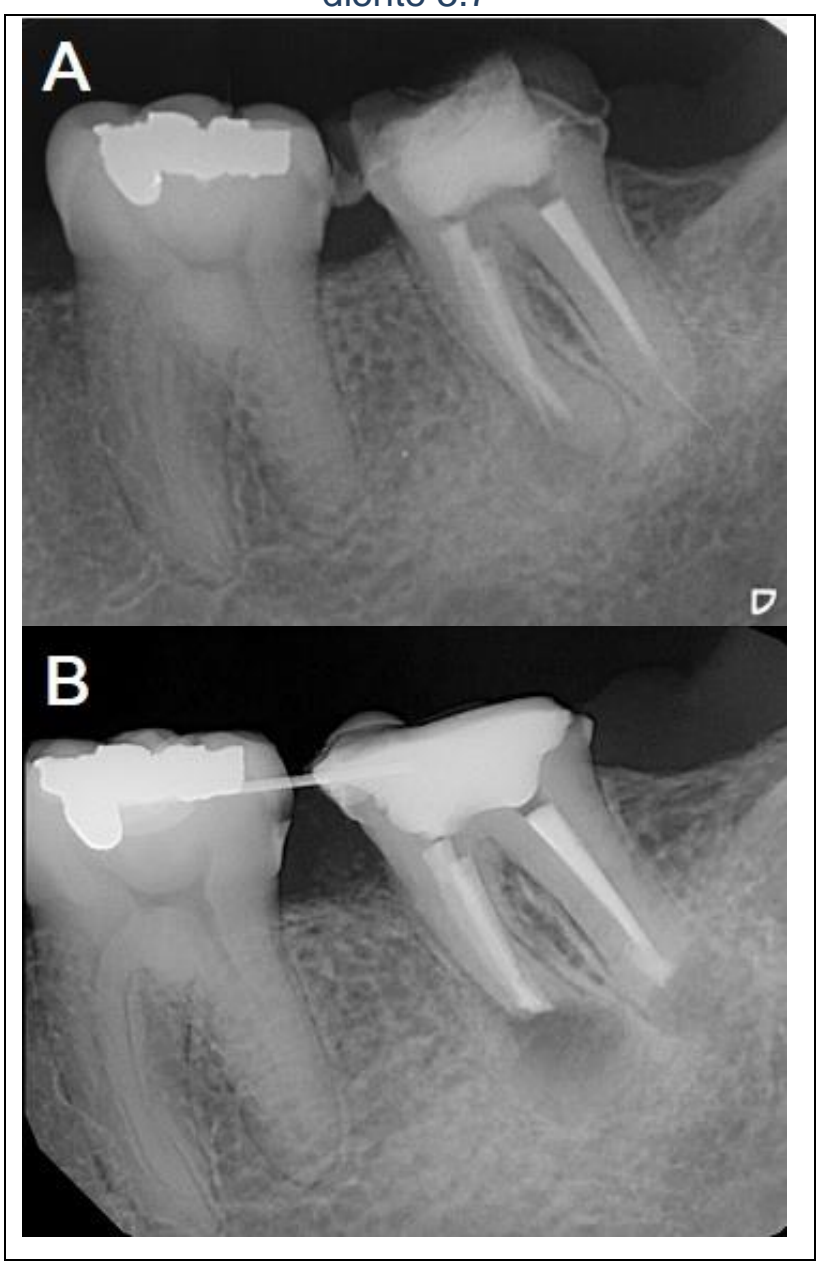

Radiografía previa (A) e inmediatamente posterior (B) al procedimiento clínico de Reimplante Intencional.

disminución de la radiolucidez apical, sin evidencia de reabsorción radicular externa o anquilosis, este último manifestado como un sonido metálico al percutir verticalmente acompañado de una pérdida del espacio periodontal en radiografía ${ }^{13}$. Un reimplante exitoso no debería provocar dolor, debe tener función masticatoria, una profundidad de sondaje en rangos de normalidad y movilidad fisiológica menor a $2 \mathrm{~mm}^{13}$.

Respecto a las complicaciones del reimplante, estas ocurren en la mayoría de los casos dentro del primer año post-tratamiento, por lo tanto, un seguimiento ideal debería ser a los 1, 3, 6 y 12 meses, extendiéndose anualmente por un mínimo de 3 años para pesquisar aquellas que se pueden desarrollar de forma tardía como la 
reabsorción radicular externa ${ }^{7,13}$. Se considera como fracaso de tratamiento cuando radiográficamente aumenta el tamaño de la radiolucidez peri-radicular inicial o hay presencia de signos y/o síntomas que evitan una función masticatoria normal, incluyendo una movilidad excesiva en sentido horizontal o vertical mayor a $2 \mathrm{~mm}$. Ante cualquiera de estas causas se debe indicar la extracción del diente reimplantado ${ }^{7}$.

\section{RESULTADOS CLÍNICOS}

Por mucho tiempo el RI fue desconocido como la última opción terapéutica para la enfermedad endodóntica post-tratamiento. Actualmente el reimplante intencional involucra varias etapas, las cuales fueron perfeccionadas a través del tiempo, con protocolos diversos, lo que explica en parte las diferentes tasas de éxito obtenidas que podían ser tan bajas como un $40 \%{ }^{17}$ o tan altas como $89.1 \%{ }^{4}$. Sin embargo, en revisiones sistemáticas recientes como la de Torabinejad et al. $(2015)^{23}$ se reportó un porcentaje de éxito del $88 \%$. En dicha revisión, pocos de los estudios incluidos utilizaron técnicas estrictamente adheridas a los principios actuales de la microcirugía endodóntica, incluso uno de los estudios seleccionados no incluyó dentro de la técnica a la retro-preparación ni retroobturación.

En revisiones más actuales el porcentaje ha aumentado levemente, Mainkar el año $2017^{4}$ presentó una tasa de supervivencia del $89.1 \%$, considerando estudios y casos que utilizaron técnicas microquirúrgicas encasilladas por el autor como "modernas". Destaca el aumento de solo un $1 \%$ con relación a Torabinejad et al. (2015), esto se explica porque Mainkar definió "técnica moderna" como "una reducción del tiempo extraoral, inferior a 15 minutos, y procedimientos que incluían retropreparación y retro-obturación", sin distinguir principios técnicos y materiales actuales como la magnificación, uso de ultrasonido y biocerámicos, por lo que la tasa de éxito podría ser aún mayor. Ahora bien, uno de los factores determinantes para el pronóstico del tratamiento y que justifica en parte el alto porcentaje estudiado por estos autores, es el tiempo extraoral del diente. Se debe considerar que un tiempo superior a 15 minutos podría afectar el pronóstico del tratamiento, lo cual ha sido recientemente ratificado por Wang et al. ${ }^{24}$. Lo anterior se basa en la preservación de la vitalidad de las células del ligamento periodontal, fundamentales para la reintegración del diente en boca y la regeneración de los tejidos peri-radiculares.

Las técnicas microquirúrgicas modernas incluyen el uso de magnificación, instrumentación ultrasónica, micro instrumentos, materiales de obturación radicular altamente biocompatibles, $3 \mathrm{~mm}$ de resección radicular en un ángulo de $0^{\circ}$, y $3 \mathrm{~mm}$ de profundidad en la retro preparación y obturación ${ }^{6}$, las cuales se han ido incorporando $\mathrm{y}$ adaptando al procedimiento de reimplante.

Respecto al material de retro-obturación, durante varios años la amalgama fue el material de elección, sin embargo, actualmente los materiales biocerámicos han demostrado una mejor capacidad de relleno y sellado, con una ventaja fundamental que es su bioactividad, precipitando cristales de apatita en las superficies dentinarias y promoviendo la regeneración ósea ${ }^{25}$.

Debido a la gran cantidad de técnicas con diferentes materiales utilizados a lo largo de los años, existe una amplia variación en las tasas de éxito reportadas, sin embargo, hay consenso en la literatura actual sobre la elección de técnicas adheridas a los principios modernos de microcirugía. Esta última ha demostrado un aumento considerable en la tasa de éxito, demostrando resultados más predecibles en comparación con las técnicas tradicionales, lo cual se puede observar en la tabla I. 
Tabla I: Adaptada de Platino et al. 2020 (25). Reimplante intencional en estudios clínicos: comparación entre técnicas.

\begin{tabular}{|c|c|c|c|}
\hline & Autor/ Año & $\begin{array}{l}\text { Numero } \\
\text { pacientes }\end{array}$ & Tasa de éxito (periodo de observación) \\
\hline $\begin{array}{l}\text { Técnica } \\
\text { tradicional }\end{array}$ & $\begin{array}{l}\text { Grossman, } 1966 \\
\text { Emmertsen \& Andreasen, } 1966 \\
\text { Koening et al., } 1988 \\
\text { Bender And Rossman, } 1993\end{array}$ & $\begin{array}{l}45 \\
90 \\
192 \\
31\end{array}$ & $\begin{array}{l}80 \% \text { (seguimiento promedio de } 5.6 \text { años) } \\
34 \% \text { (seguimiento mínimo de un año) } \\
82 \% \text { (seguimiento de } 6 \text { a } 51 \text { meses) } \\
80,6 \% \text { (seguimiento de } 1 \text { día a } 22 \text { años) }\end{array}$ \\
\hline \multirow{5}{*}{$\begin{array}{l}\text { Técnicas } \\
\text { basadas en } \\
\text { principios } \\
\text { modernos de } \\
\text { microcirugía }\end{array}$} & Choi et al., 2014 & 285 & $89,5 \%$ (seguimiento medio de $25,4 \pm 9,3$ \\
\hline & Asgary et al., 2014 & 20 & $\begin{array}{l}90 \% \text { (promedio de seguimiento de } 15.5 \\
\text { meses) }\end{array}$ \\
\hline & Cho et al., 2016 & 196 & $\begin{array}{l}\text { 93\% (tasa de retención acumulada a los } 12 \\
\text { años) }\end{array}$ \\
\hline & Jang et al., 2016b & 41 & $\begin{array}{l}83,4 \% \text { (a los } 4 \text { años) y del 73,0\% (a los } 11 \\
\text { años) }\end{array}$ \\
\hline & Cho et al., 2017 & 103 & $89 \%$ (al año) y de $68 \%$ (a los 4 años) \\
\hline
\end{tabular}

Actualmente el RI es una aceptada opción de tratamiento, alcanzando resultados superiores a su contraparte tradicional, siendo un tratamiento predecible que debe ser discutido con los pacientes como una alternativa a la extracción cuando los tratamientos endodónticos no quirúrgicos o microcirugía endodóntica no son factibles. Por otro lado, se debe considerar que los pacientes no siempre pueden costear otras opciones de tratamiento, por lo que el reimplante intencional se debe proponer como una alternativa viable para conservar el diente natural, incluso con mejor relación costo-efectividad que el implante dental ${ }^{5,9}$. Esto último considerando que el costo para el paciente es similar a una microcirugía apical, y le permite conservar su corona clínica siendo los tiempos de rehabilitación o restauración más rápidos $\mathrm{o}$ incluso inmediatos si es que la pieza involucrada ya se encuentra rehabilitada y en función.

En cuanto a las posibles complicaciones que se pueden desarrollar posterior al procedimiento se encuentra la reabsorción radicular externa y la anquilosis, reportando una incidencia de $3-4.9 \%$ y $0-7 \%$, respectivamente ${ }^{4}$. La anquilosis por sí misma no afecta el pronóstico del diente, pero puede afectar la calidad ósea de dos maneras; generando defectos óseos en niños durante su crecimiento ${ }^{26}$, o provocar mayor pérdida ósea cuando se requiera extraer el diente, debido al mayor trauma que eventualmente se puede generar durante la extracción ${ }^{4}$. Los controles y seguimiento periódico del diente reimplantado permiten detectar precozmente estas alteraciones para, de ser necesario, realizar la extracción sin mayor dificultad. Diversos estudios demuestran que cuando el tiempo extraoral del diente a reimplantar es menor a 15 minutos la incidencia de anquilosis es tan baja como un $3 \%{ }^{13}$. Es importante recalcar que un diente anquilosado no necesariamente desarrollará un proceso reabsortivo radicular externo, por lo que puede ser mantenido en boca sin complicaciones durante prolongados periodos de tiempo, y si posterior a esto son extraídos, el éxito de un futuro implante en la zona no debería verse afectado ${ }^{4}$. Tal como se mencionó anteriormente, si bien la mayoría de las complicaciones ocurre dentro del primer año, la reabsorción radicular externa se puede presentar hasta el tercer año post-tratamiento ${ }^{13}$, por lo que el seguimiento debe extenderse por todo este periodo. 


\section{CONCLUSIÓN}

En casos de enfermedad endodóntica posttratamiento, donde no es posible una resolución vía ortógrada o mediante microcirugía apical, el reimplante intencional se debe considerar como una alternativa viable de tratamiento. Si el RI es realizado siguiendo los principios técnicos y biológicos de la microcirugía endodóntica actual, el pronóstico es favorable con una tasa de supervivencia promedio del $89.1 \%$ y con baja incidencia de complicaciones, siempre y cuando la selección de caso sea la adecuada.

\section{REFERENCIAS}

[1] Haapasalo M, Shen Y, Ricucci D. Reasons for persistent and emerging post treatment endodontic disease. Endod Topics. 2008;18(1):31-50.

DOI:10.1111/j.1601-1546.2011.00256.x

[2] Siqueira JF. A etiology of root canal treatment failure: why well-treated teeth can fail. Int Endod J. 2001;34(1):1-10. DOI:10.1046/j.1365-2591.2001.00396.x

[3] Becker BD. Intentional replantation techniques: A critical review. J Endod. 2018; 44(1):14-21. DOI:10.1016/j.joen.2017.08.002

[4] Mainkar A. A systematic review of the survival of teeth intentionally replanted with a modern technique and costeffectiveness compared with singletooth implants. $\mathrm{J}$ Endod. 2017;43(12):1963-8.

DOI:10.1016/j.joen.2017.08.019

[5] Chogle S, Chatha N, Bukhari S. Intentional Replantation of Teeth is a Viable and Cost-effective Alternative Treatment to Single-Tooth Implants. J Evid Based Dent Pract. 2019;19(1):86-8 DOI:10.1016/j.jebdp.2018.12.001

[6] Grzanich D, Rizzo G, Silva RM. Saving Natural Teeth: Intentional Replantation-Protocol and Case Series. J Endod. 2017;43(12):2119-24. DOI:10.1016/j.joen.2017.08.009

[7] Jang Y, Lee SJ, Yoon TC, Roh BD, Kim E. Survival rate of teeth with a Cshaped canal after intentional replantation: A study of 41 cases for up to 11 years. J Endod. 2016;42(9):1320-5. DOl:10.1016/j.joen.2016.05.010

[8] Coaguila H, Zubiate J, Mendiola C. Una visión del reimplante intencional como alternativa a la exodoncia dentaria. Rev Estomatol Herediana. 2015;25(3):224-31 . DOI:10.20453/reh.v25i3.2615

[9] Deshpande NM, Shah D, Wadekar S. Maintenance of cell viability in extraoral conditions for a case of intentional replantation to retrieve a separated endodontic instrument. J Conserv Dent. 2019; 22(2):207-12. DOI:10.4103/JCD.JCD_461_18

[10] Hayashi M, Kinomoto Y, Takeshige F, Ebisu S. Prognosis of intentional replantation of vertically fractured roots reconstructed with dentin-bonded resin. $J$ Endod. $2004 ; 30(3): 145-8$.

DOI:10.1097/00004770-20040300000005

[11] Peñarrocha M, García B, Martí E, Palop M, Von Arx T. Intentional replantation for the management of maxillary sinusitis. Int Endod J. 2007;40(11):891-9. DOI:10.1111/j.1365-2591.2007.01278.x

[12] AAE and AAOMR Joint Position Statement: use of cone beam computed tomography in endodontics 2015 update. J Endod. 2015;41(9):1393-6. DOI:10.1016/j.joen.2015.07.013

[13] Cho SY, Lee Y, Shin SJ, Kim E, Jung I, et al. Retention and healing outcomes after intentional replantation. $\mathrm{J}$ Endod. 2016;42(6):909-15.

DOI:10.1016/j.joen.2016.03.006

[14] Choi YH, Bae JH, Kim YK, Kim HY, Cho $\mathrm{BH}$. Clinical outcome of intentional replantation with preoperative orthodontic extrusion: a retrospective study. Int Endod J. 2014;47(12):1168-76. DOI:10.1111/iej.12268

[15] Peer M. Intentional replantation-a 'last resort' treatment or a conventional treatment procedure? Nine case reports. Dent Traumatol. 2004;20(1):48-55. DOI:10.1046/j.1600-4469.2003.00218.x

[16] Marouane O, Turki A, Oualha L, Douki N. Tooth replantation: An update. Méd Buccale Chir Buccale. 2017;23(2):103-10. DOI:10.1051/mbcb/2016056

[17] Kim S, Kratchman S. Modern endodontic surgery concepts and practice: a review. J 
Endod.

2006;32(7):601-23.

DOI:10.1016/j.joen.2005.12.010

[18] Bernardes RA, de Souza Junior JV, Duarte MAH, De Moraes IG, Bramante CM. Ultrasonic chemical vapor deposition-coated tip versus high- and low-speed carbide burs for apicoectomy: time required for resection and scanning electron microscopy analysis of the root-end surfaces. J Endod. 2009;35(2):265-8. DOI:10.1016/j.joen.2008.11.009

[19] Carr GB, Murgel CAF. The use of the operating microscope in endodontics. DOI:10.1016/j.cden.2010.01.002

[20] Nair U, Ghattas S, Saber M, Natera M, Walker C, et al. A comparative evaluation of the sealing ability of 2 root-end filling materials: an in vitro leakage study using Enterococcus faecalis. Oral Surg Oral Med Oral Pathol. 2011;112(2):74-7. DOI:10.1016/j.tripleo.2011.01.030

[21] Shokouhinejad N, Nekoofar MH, Razmi $H$, Sajadi S, Davies TE, et al. Bioactivity of EndoSequence Root Repair Material and Bioaggregate. Int Endod J. 2012;45(12):1127-34.

DOI:10.1111/j.1365-2591.2012.02083.x

[22] Rouhani A, Javidi B, Habibi M, Jafarzadeh $\mathrm{H}$. Intentional replantation: a procedure as a last resort. J Contemp Dent Pract. 2011;12(6):486-92. DOI:10.5005/jp-journals-10024-1081

[23] Torabinejad M, Dinsbach NA, Turman $M$, Handysides $R$, Bahjri $K$, et al. Survival of intentionally replanted teeth and implant-supported single crowns: a systematic review. J Endod. 2015; 41(7):992-8.

DOI:10.1016/j.joen.2015.01.004

[24] Wang L, Jiang $H$, Bai $Y$, Luo $Q$, Wu $H$, et al. Clinical outcomes after intentional replantation of permanent teeth: $A$ systematic review. Bosn J of Basic Med Sci. 2020;20(1):13-20.

DOI:10.17305/bjbms.2019.3937

[25] Plotino G, Abella F, Duggal M, Grande $\mathrm{N}$, Krastl $\mathrm{G}$, et al. Clinical procedures and outcome of surgical extrusion, intentional replantation and tooth autotransplantation - a narrative review. Int Endod J. 2020;53(12):163652. DOI:10.1111/iej.13396
[26] Malmgren $\quad B . \quad$ Ridge preservation/decoronation. $\mathrm{J}$ Endod. 2013;39(3):67-72.

DOI:10.1016/j.joen.2012.11.056

CÓMO CITAR ESTE ARTÍCULO

Dufey N, Peña-Bengoa F, Lazo L. Reimplante intencional como ultima opcion de tratamiento frente al fracaso endodontico. Revisión narrativa. Appli Sci Dent. 2021:1(1);21-31

DOI: 10.22370/asd.2021.1.1.2507

Applied Sciences in Dentistry, revista científica de la Facultad de Odontología de la Universidad de Valparaíso, de Acceso Abierto y de Publicación Continua.

Son aceptados trabajos originales e inéditos, abarcando cartas al editor, comunicaciones breves, artículos de investigación, casos clínicos y revisiones bibliográficas.

Correo electrónico de contacto:

contacto.asdj@uv.cl

editor.asdj@uv.cl

Página Web:

https://revistas.uv.cl/index.php/asid

Redes Sociales

Instagram @asd.journal

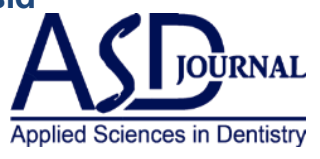

